\title{
The Research Process and the Library: First-Generation College Seniors vs. Freshmen
}

\section{Elizabeth Pickard and Firouzeh Logan}

In a follow-up study to the ERIAL (Ethnographic Research in Illinois Academic Libraries) Project, librarians at UIC compared the responses of first-generation college freshmen from the original study to those of seniors. The study's aim was to determine whether student information literacy increases as a result of undergraduate education and to further explore the student research process with respect to the particular factors that inform and effect change in it. The findings showed that information literacy increased among these students, and they developed a more complex approach to the research process and the library.

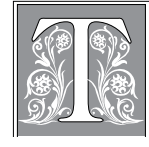

hree years ago, as part of the ERIAL (Ethnographic Research in Illinois Academic Libraries) research team, librarians at the University of Illinois at Chicago (UIC) studied the research process of 33 first-year college students and interviewed 15 faculty and 13 librarians. Broadly speaking, the aim of the study was to identify and examine the expectations that faculty, librarians, and students have of one another. More specifically, the aim of the project was to find out what students, especially those in the underserved and nontraditional groups identified by each library, actually do when they are assigned a research project for one of their class assignments.

UIC is a state-funded public research institution located in the near west side of Chicago that serves a very diverse group of approximately 27,000 students. The student population includes 1.4 percent international students, ${ }^{1}$ many recent immigrants to the United States, and 29 percent transfer students from other colleges. ${ }^{2}$ A report by the UIC Vice Chancellor's Office showed that 25 percent of UIC freshmen were the first in their families to attend a four-year university (in other words, were first-generation college students). ${ }^{3}$ Using ACT scores, the report also suggested that first-generation college students come to college at a disadvantage. Because first-generation college students constitute a large portion of the student body at UIC, the UIC ERIAL team focused its study on this group. The aim was to identify these students' expectations of libraries before they developed UIC-specific research habits and to see how they went about producing scholarly work. Understanding how these students actually do their research

Elizabeth Pickard is Liaison, College of Education, and Assistant Professor, Reference Department; and Firouzeh Logan is Head, Reference Department, and Assistant Professor in Richard J. Daley Library at University of Illinois at Chicago; e-mail: epickard@uic.edu, flogan@uic.edu. (c) 2013 Elizabeth Pickard and Firouzeh Logan, Attribution-NonCommercial (http://creativecommons.org/licenses/by-nc/3.0/) CC BY-NC 
would allow the library to better tailor services to meet these students' research needs and possibly help them overcome any disadvantages with which they might start college.

The ERIAL project found that freshmen struggled with a range of information literacy skills such as understanding how to find books on shelves and how to search for and evaluate sources. They did not seem aware of librarians' expertise with respect to performing research and using resources such as journal article databases and catalogs, nor were they generally aware of the resources the library provided to facilitate such searching. Furthermore, freshmen first-generation college students appeared to perceive research as a single-step endeavor rather than as a process. These findings led the UIC ERIAL team to wonder how differently senior first-generation college students might approach research. The team wanted to ascertain if, after four years, students had in fact acquired better information literacy skills and were making more use of librarians' expertise. By addressing this significant question for librarians, this research study also unexpectedly addressed larger higher education questions about whether and what undergraduates learn during their college years.

\section{Literature Review}

Libraries aim to facilitate research through the provision of resources, sources, and services, including teaching research skills to patrons. According to the Ithaka S+ R Survey 2010, 94 percent of academic library directors view teaching undergraduates information literacy skills as one of the library's primary roles and believe the library should serve as a principal point in the discovery process. ${ }^{4}$ To successfully facilitate research in these ways, libraries must address the approaches students take to research and the fact that these approaches may change with time and experience. This means libraries must understand the specific steps that constitute the student research process as well as the particular factors that both inform and effect change in it. Surveys, alone, may not be sufficient tools. Derek Rodriguez, author of the Understanding Library Impacts protocol, states, "Using both quantitative and qualitative methods helps us understand how and why libraries support students when the stakes are highest." ${ }^{5}$

Ethnography is a qualitative approach to data collection and analysis that provides a useful flexibility. Ethnographic methods allow participants to use their own language to describe situations and processes, which is beneficial in two ways: participants' different vernaculars are, themselves, a source of information, and the lack of preselected answers a) prevents a participant from selecting an answer just to have selected something and b) allows for the emergence of unanticipated responses. In a call for using ethnography to "capture the changing information landscape" of academic libraries, Gina Hunter and Dane Ward explain, "Much of what libraries want to know about how students study or conduct research is not amenable to survey research. Students may be unaware of their own research strategies or may not share the same vocabulary for their information needs as librarians." ${ }^{6}$ Likewise, researchers at Eastern Michigan University stated, "The open dialogue [of ethnographic methods] allowed the interviewees to move into new and unexpected directions, adding depth and breadth to our understanding of library usage." ${ }^{7}$ Furthermore, Michelynn Mcknight found, in a review of studies on information-seeking behavior, that there were consistent discrepancies between how participants actually go about seeking information and what they report on surveys. ${ }^{8}$ Clifford Geertz, a seminal author in the field of anthropology, explains that a significant power of ethnography lies in its ability to create a sense of "being there": ${ }^{9}$ in other words, that it reflects the researcher having "penetrated" an 
unknown way of life, ${ }^{10}$ (in this case, student research).

There are not many prior studies that examine first-generation college students' research process and/or use of the library. Jordan Yee describes a seminar for firstgeneration college seniors that DeVry University employed to fill service gaps librarians had observed, but it was not a formal research study. ${ }^{11}$ An older study performed by Raymond V. Padilla et al. at a college in the southwest used qualitative analysis to examine college success among sophomore through senior minority students, and it happened that many of them were the first in their families to attend a four-year university. ${ }^{12}$

Other studies also used ethnographic means of exploring research and library use among first-generation college students. A study at California State University looked at library use specifically among Latino students, ${ }^{13}$ while a study at California State University Fresno looked at library use across first-generation college students. ${ }^{14}$ However, neither study looked at library use as part of the research process. Researchers at the University of the Arts London (UAL) interviewed first-generation college students about their use of the library; but, unlike the study this article describes, they did not differentiate between seniors and freshman. ${ }^{15}$

While not always addressing firstgeneration college students specifically, prior studies have made use of ethnographic methods to examine the student research process. However, they also have not compared freshmen to seniors. In exploring undergraduate students' perceptions of information literacy, Firouzeh Logan and Elizabeth Pickard explored the research process of freshmen first-generation college students at the University of Illinois at Chicago as part of the Ethnographic Research in Academic Libraries (ERIAL) project. ${ }^{16}$ Likewise, Melissa Gross and Don Latham interviewed and tested freshmen at Johns Hopkins. ${ }^{17}$ In contrast, Alison Head and Michael Eisenberg did not look at freshmen, but interviewed sophomores, juniors, and seniors across multiple college and university campuses to look at how students conduct research and evaluate information. ${ }^{18}$ The studies that have compared research processes of freshmen and seniors did not use ethnographic approaches. At the University of Northern Colorado, researchers used a survey and participant self-tests to assess library literacy progress and found discrepancies in the results between the two methods. ${ }^{19}$ At Johns Hopkins, researchers used only surveys to compare the library skills of freshmen and upperclassmen..$^{20}$

The project this article describes sought to more fully explore potential differences in the research processes of freshmen and seniors, especially with respect to first-generation college students. It is a follow-up to the ERIAL study done by Logan and Pickard at the University of Illinois at Chicago ${ }^{21}$ and compares the research behavior and perspectives of firstgeneration college seniors to those of the freshmen using the same ethnographic methods employed in the original study.

\section{Methodology}

This study compared the responses of seniors to the responses of freshmen participants in the ERIAL project. The researchers asked seniors the same six questions they analyzed for the chapter "First-Generation College Students: Their Research Process" in the ERIAL project book College Libraries and Student Culture: What We Now Know. ${ }^{22}$ Because the original ERIAL project at UIC targeted freshmen to gather information before students' experience at UIC had informed their expectations of its library, researchers did not interview college seniors at that time. Thus, researchers for this project sought to recruit a comparable set of college seniors to interview. The original ERIAL project interviewed freshmen from May 2009 through July 2010. Researchers recruited and interviewed seniors less than a year later, from March through April 2011, such that the freshmen and seniors 
were part of the same cohort. Both freshman and senior participants would have experienced much the same university and library. In fact, at the time researchers interviewed senior participants, the freshmen participants from the original study would not yet have graduated.

The researchers recruited participants via a batch e-mail sent to students identified in the library database as seniors. Students were offered a $\$ 25$ gift certificate for the university bookstore as an incentive for completing an interview. Interested students responded by phone or e-mail and were directed to a SurveyMonkey survey on which they reported whether they were seniors and were the first members of their immediate families to attend college. The researchers then contacted qualified students to arrange interviews. To create a comparable set of data, the investigators interviewed a comparable number of seniors as they had freshmen. The researchers audiorecorded and transcribed the interviews. As with the original ERIAL project, researchers used a version of grounded theory ${ }^{23}$ to code the transcription scripts for themes. This approach allowed themes to arise from the data. Researchers coded each participant's answers to the interview questions by labeling themes that emerged (coding). In an iterative process, researchers next compared the answers across all participants to hone the codes and then to make comparisons.

\section{Findings}

\section{Searching}

Seniors appeared generally more comfortable and adept at performing and talking about research. They seemed more informed about their options in terms of available resources, where to look for them and how to use them, and they approached searching as a multistep process.

Like freshmen, seniors still only searched online, but they spoke of and used online resources with more specificity. While 17 percent of freshmen named specific library databases, the rest used the term "online" to mean anything from the library website (which they discussed as one thing, not differentiating between the website, the catalog, and the databases) to Google. ${ }^{24}$ Freshmen rarely discussed the exact online location where they searched. Seniors, however, often discussed specific databases and library resources. Of the seniors interviewed, 50 percent mentioned specific library-funded databases. This is an increase of 33 percent over freshmen. Furthermore, while freshmen only mentioned JSTOR and the catalog, seniors discussed using a breadth of different library resources including JSTOR, PsycInfo, LexisNexis, ARTstor, the library catalog, "library databases" generally, as well as LibGuides. Seniors were also more aware that the library provided these databases. In representative comments, one freshman explained that he used JSTOR, a university resource, "but all the books I got were from the library," ${ }^{25}$ while seniors generally spoke of resources in terms of "a Library database, like LexisNexis." Seniors had parsed the bulk concept "online" that freshmen used. Seniors' detailed discussion of their online searching suggests a greater awareness of available resources and familiarity with the library.

When prompted with the question "did you use print materials," seniors again presented deeper understanding about using resources. The question was intended to open a discussion of using print indices without leading the interviewee to "print indices" as an answer. While both freshmen and seniors interpreted the question as referring to the use of books or print journals as sources, the idea of a print resource for finding citations actually occurred to 12 percent of seniors. In discussing the use of library databases to find journal articles, one said, "I don't know how you can possibly look for things physically" and another, "there is nothing physical to search through." The fact that a print possibility occurred to these students at all suggests that they 
had a relatively complex understanding of the function of databases. In their discussion of (the lack of) "physical" search options, seniors revealed their awareness of the databases as tools for organizing as well as accessing information. Seniors not only specified that they used databases, and often named them, but seniors understood that the function of a database was not simply to link to the full text of articles but to organize the citations to facilitate the act of searching.

Seniors, unlike most freshmen, presented the perception of research as an iterative process. The ERIAL study of freshmen at UIC paralleled the finding of Gross and Latham, who explain that, among freshmen, "[t]he idea that successful information seeking need only be measured by the ability to find the information, not the process used to get there, was repeated time and time again." 26 Findings at UIC showed that both freshmen and seniors preferred to use online resources because they were "easier," "faster," or "more convenient" to use. Freshmen spoke of convenience generally, not differentiating between searching and access as steps ${ }^{27}$ whereas seniors actually specified that it was getting the full text that they found easier. This more detailed discussion indicates a fuller understanding of the searching process with respect to the existence of multiple steps: there is a searching step or steps and an accessing full-text step. Likewise, among seniors, 17 percent recognized the need to explore different search terms, and 11 percent talked about manipulating search terms or Boolean operators to narrow their searches, all of which inherently imply the performance of multiple searches. The exploration of different search terms did not emerge at all in conversations with freshmen. Moreover, some seniors reported making more thorough use of the sources they found. Of the seniors interviewed, 11 percent discussed using bibliographies of articles they had found to identify additional sources on their topics. Freshmen did not discuss this approach to, or understanding of, the potential use of sources. Like exploring search terms, using a source to find additional sources inherently indicates the performance of multiple searches and did not emerge in interviews with freshmen.

In general, seniors described searching in ways that indicated more acumen in the use, as well as awareness, of resource options. The majority of both freshmen and seniors saw the library as a source of authoritative information, yet seniors knew more about how to find, use, and get help using those resources. As described earlier, seniors knew enough about sources, citations, and authority to use an existing bibliography to find other sources. One senior actually recognized the overlap in journals among databases. Seniors also discussed specific services and aspects of the physical library that freshmen never acknowledged. Seniors referred to "Reference Librarians" and the "Circulation Desk," whereas most freshmen often did not know that reference librarians existed, much less what they did. ${ }^{28}$ Seniors also noted different locations and services specific to the UIC Library, such as the "reference area," "architecture call numbers," "I-Share" (a service through which multiple Illinois college libraries share books with each other) and the "IM" reference service. This awareness and detailed description of the UIC Library further suggests that seniors were more familiar with the UIC Library than freshmen were.

\section{Source Selection: Quantity}

As shown among freshmen, students often struggle with how many sources to find and to include in their bibliographies. Freshman and senior interviewees were similar in how they went about determining when they had enough sources. However, seniors tended to be more rigorous in their collective approach.

Adequately covering the topic was the primary consideration of both freshmen and seniors. Only 10 percent of seniors as compared to 17 percent of freshmen 
discussed considering the size/length of their project as a parameter in choosing how many sources they used, and all of these interviewees discussed their desire to be able to cover their topic. ${ }^{29}$

Both freshmen ${ }^{30}$ and seniors wanted to make sure they at least met the instructor's requirements (if there were any) for a minimum number of sources. Freshmen often also had to work within a maximum number of sources as set by their instructors and often found this too limiting to adequately cover the topic. ${ }^{31}$ Seniors did not discuss a set maximum, but, like the freshmen, worked also to adequately (according to their own standards) cover the topic.

While 55 percent of freshmen selected their number of sources based on being able to cover their topics, ${ }^{32}$ they spoke generally of being able to do so. One freshman interviewee gave a typical explanation: " I knew I needed 4, but I went ahead and used probably 6...[O]nce I had that [the topic] covered, I knew that was enough." ${ }^{33}$ Seniors, however, often went beyond covering the topic to exhausting it. Of senior interviewees, 83 percent discussed covering the topic as a significant consideration in selecting how many sources they used. This represents a 33 percent increase as compared to freshman interviewees. Furthermore, 28 percent of seniors tried to search exhaustively, meaning they did not stop adding new sources until they began to continually encounter the same information. None of the freshmen spoke of searching until the information became redundant. One senior interviewee described searching exhaustively, stating, "We saw similarities and stopped after we saw the third or fourth thing that was the same." Another stated, "We knew we had enough because some of the stuff we found was repetitive." This approach suggests that seniors, who most likely have more experience doing research than freshmen, have become more comfortable with benchmarks of the research process. They seem to understand more of the specific qualities that mark academic research.

\section{Source Selection: Type}

When asked how they knew when they had the right kinds of sources, senior interviewees responded similarly to freshmen in terms of general concepts. Both groups discussed relevance and authority as qualities determining selection. However, once again, seniors demonstrated a more complex and specific understanding of source evaluation.

\section{Relevance}

As expected, all senior and freshman interviewees indicated that the relevance of a source to their topic was a significant criterion in selecting that source. The specifics of determining relevance, however, differed greatly between freshmen and seniors. Freshmen usually looked for the amount of information a source contained and chose those sources that contained the most. ${ }^{34}$ One freshman stated in a representative comment that he chose sources based on "the amount of information I was able to pull from them." ${ }^{35}$ Freshmen also mimicked their professors' language; for example, as one freshman interviewee put it, "I kind of tried to have an equal amount of sources that agreedthat I agreed with - and then disagreed with...so that my professor could see I was trying to see both sides of the story." ${ }^{\prime 36}$ His language, like many other freshman interviewees, very closely reflected the language used by UIC English 161 faculty in their research assignments.

In contrast, seniors used what seemed to be their own language, language that suggested a more detailed understanding of, and rigorous approach to, research, as well as descriptions of source selection that indicated that they saw research as a process instead of a one-shot effort. Seniors employed many different words to describe topic support than freshmen did. Whereas freshmen generally described the process with comments such as " $[t]$ hey were talking about the same thing I was, ${ }^{\prime 37}$ seniors gave details of the par- 
ticular parts of their paper that sources supported, and seniors evaluated more aspects of their sources for such support. Seniors described determining relevance with comments such as "when it was supporting my thesis or hypothesis" and "when I can look at their [the sources'] references and they agree with what the authors are saying and what I'm saying." As indicated here, seniors made use of not only the sources but of their sources' bibliographies. Freshman interviewees did not. Senior interviewees used these citations to find additional sources, to verify the validity of the research, and, as the next section will discuss, to rank sources by levels of authority.

Furthermore, seniors discussed selecting sources in terms of being comprehensive as well as exhaustive. Several seniors, unlike freshmen, wanted to make sure they had found every published source on their topic (in other words, were comprehensive in their searching). Seniors also discussed wanting to exhaust their topics, meaning stopping their search for sources only when the information new sources provided had been covered by sources they had already found. Seniors generally continued searching until they found redundant information several times via several different searches. They seemed to accept that a rigorous search for sources required more than one attempt at searching. By contrast, freshman interviewees often wanted to make sure they had adequately covered their topics - they wanted to find "enough" 38 - but they did not discuss their search processes as being so extensive that the repetition of information among sources became the cue to stop. While not all seniors discussed employing these concepts, about 30 percent mentioned trying to be either comprehensive or exhaustive in their searches, whereas only 6 percent of freshmen mentioned either at all. ${ }^{39}$ The idea of doing a comprehensive and/or exhaustive search inherently suggests an investment of time and effort. Freshmen often described having difficulty finding sources on their topics when they perceived a search as taking too much time, or if they had to repeat it. ${ }^{40}$ Therein, the senior interviewees seem to have developed more accurate expectations as well as a more accurate understanding of the research process. Likewise, they seemed to perceive research as a process rather than expecting to find all sources in a single step. Finally, a small percentage of seniors discussed the need for primary versus secondary sources. This criterion did not arise in conversations with freshman interviewees, but its omission could have resulted from the different level of seniors' assignments.

\section{Authority}

Over 50 percent of the senior interviewees discussed determining authority of their sources. This is a 20 percent increase over freshman interviewees, of whom only 30 percent discussed authority as a selection criterion. ${ }^{41}$ There were also significant differences in the methods senior and freshman interviewees used to evaluate sources for authority as well as in the language they used to describe their processes.

While both freshman and senior interviewees associated university resources with scholarly sources, seniors in particular referred to the library as the provider of authoritative information. Of the freshman interviewees, 17 percent mentioned that information found on the UIC website or found at the library would be scholarly. ${ }^{42}$ Among the seniors, only the library was mentioned.

One of the most substantial differences between the freshman and senior interviewees was in the seniors' use of citation tracking. In a statement characteristic of these seniors, one interviewee explained, “Usually, while looking online, I just looked for the titles that were more relevant to what I was trying to base my paper on. And, I guess how many people are cited, because sometimes there are more citations to it." Only one (5\%) of the freshman interviewees used the number 
of times a source had been cited to evaluate that source's authority. ${ }^{43}$ In contrast, 17 percent of seniors did so. This represents a 12 percent increase and, potentially, an increase in mastery of the research process among the senior interviewees.

Another significant difference lay in the language freshmen and seniors used to explain how they evaluated sources for authority. Freshman interviewees used general terms such as "scholarly," "reliable," "peer-reviewed," "written by professors," and "looks fancy" as indicators that a source was scholarly, ${ }^{44}$ while seniors listed more specific details. Senior interviewees' responses indicated an understanding of the particulars that make a source "scholarly." In a comment typical of senior interviewees, one detailed that she evaluated sources by "basically, looking at the publication, the authors, where they published-things of that nature-PsycInfo-you're not going to find anything that's not scholarly." Such comments also provided more specifics about why library databases might be better resources for scholarly information than Google and even sometimes parsed that. Another senior interviewee stated, "I know that it's [Google Scholar] a scholarly website. Everything on there is like research-based." None of the freshmen discussed authority in such specific terms.

\section{Comprehensible}

While 11 percent of freshmen rejected sources they did not understand, ${ }^{45}$ no seniors discussed rejecting sources based on this criterion. This finding also suggests an increased understanding of the specifics of the research process by seniors.

The fluency with which senior interviewees discussed source selection was a quality that surveys could not have captured, as it was an unanticipated finding and one that emerged via conversation. Seniors discussed searching comprehensively and exhaustively as well as providing specific details about evaluating sources for authority that would have been both difficult to anticipate and potentially leading in a multiple-choice response scenario.

\section{Obstacles Encountered}

Seniors were asked if they had encountered obstacles while doing their research. Some of the seniors' responses to this question were similar to those of the freshmen, but the words describing their problems and issues were much more detailed and specific. Of the seniors, 20 percent mentioned time, not just time management, but they specified that they had other obligations such as jobs and family. Of the seniors, 50 percent mentioned having problems finding things such as data, statistics, scholarly "stuff," articles, full-text articles, enough resources, and relevant and useful resources. Not all the seniors were looking for the same types of sources, but, unlike the freshmen, they knew the difference between the library not collecting something and its simply not being available or even not existing. Head and Eisenberg generally concluded that students' challenges were often related to their "perceived inability to find desired materials." ${ }^{46}$ At UIC, some seniors, like the freshmen, did maintain that the library had nothing or not enough on their topic, or that the information available on their topic was incorrect. However, this was not true across all senior participants. Head and Eisner included sophomores in their analysis and the difference in their findings may stem from the inclusion of lowerclassmen. Furthermore, like the students in "Undergraduate Perceptions of Information Literacy" 47 and the "Students Research the Library" ${ }^{\prime 4}$ studies, both the freshmen and the seniors who did not use the library well had a very high level of confidence in their ability to find information. Nevertheless, the seniors were much more specific about their problems, even though some were not library-centric.

Seniors, unlike freshmen, discussed having struggled with English. Some seniors mentioned they had not spoken English well when they began school and had not used American libraries. They 
explained that they were not familiar with organizational tools such as call numbers and were handicapped by limited English writing skills and grammar. The researchers theorize that seniors may have been comfortable enough with their English to describe this struggle, whereas freshmen may have avoided participating in the study precisely because they were still struggling with their English. These obstacles may be useful to consider among schools such as UIC, which have significant numbers of international students as well as students who are recent immigrants to the United States.

\section{Getting Help}

Freshmen and seniors differed greatly in the types of help they sought and the people to whom they turned for that help. In general, seniors were more selfsufficient, but also made more thorough use of librarians and spoke more comfortably and accurately about the research process.

Seniors asked for help less often than freshmen but were clearly more familiar with the research process and library resources. When asked if they sought help from anyone, only 55 percent of seniors said they had. This is a 35 percent drop compared to the responses of freshmen. ${ }^{49}$ However, most seniors spoke of having asked for help in the past from instructors, librarians, and the Writing Center. In fact, several seniors discussed having used a variety of library services and consulted experts on past projects even if they did not do so on their most recent one. Several seniors, as compared to a single freshman, mentioned having used the Writing Center in the past. Likewise, seniors discussed having used services that freshmen never even mentioned such as IM and e-mail reference services. Furthermore, seniors differentiated among library services and locations in ways freshmen did not. Seniors discussed contacting librarians in "reference," the "reference librarians," "reference desk," "circulation desk," and "course reserves," whereas freshmen usu- ally referred to the "library" or speaking to a "librarian" regardless of the specific area they visited or point of service they used. This apparent increase in fluency with library particulars suggests an increased familiarity with the library that seems to have resulted from regular use of those particulars. One senior echoed the sentiments of many interviewees, stating, "I feel pretty well-versed in how to use a library. You spend so much time doing research during undergrad that, if you don't know how to use a library, then you really didn't get much out of your education." Seniors worked more independently than freshmen, but were working with more awareness of the resources and services the library offers. Seniors may have been able to work independently because, somewhere along the way, they discovered and learned to use the library's resources and expertise.

In point of fact, when seniors did seek help with research, they sought it primarily from librarians and next most frequently from their instructors and then peers (see figure 1). This was a marked change from freshmen. Of the seniors, 54 percent sought help from librarians compared to only 22 percent of the freshmen who sought help most frequently from their instructors and next from their friends. ${ }^{50}$ Among freshmen, librarians ranked third as a source of help and were primarily used for physically getting to sources.

In contrast, seniors made more thorough use of librarians' expertise and only occasionally asked librarians for help physically locating sources. Instead, they usually asked librarians for help with more complex use of databases and refining search terms. Seniors described this type of help from librarians characteristically as "they would show me how to narrow it [my search] down," "I ask the Reference Desk to help me search," and "I ask at the Reference Desk about which databases to use." Many seniors also mentioned a variety of different databases by name, many of them fairly special- 


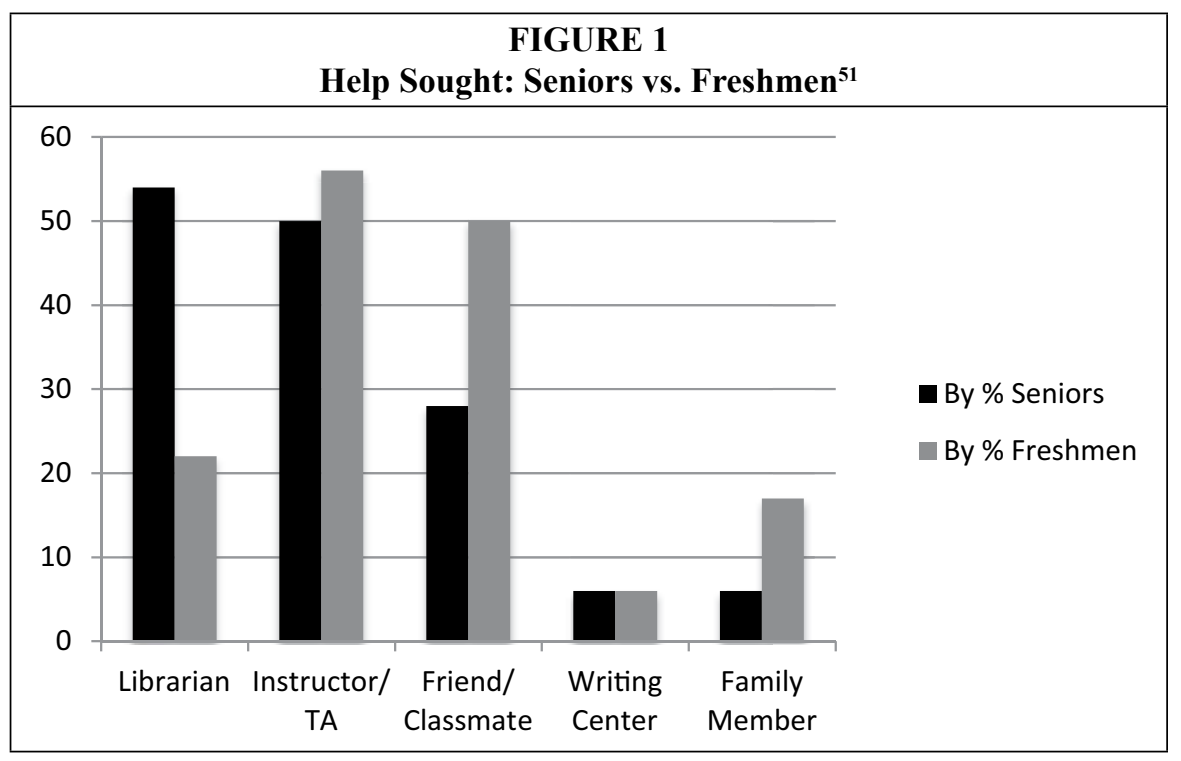

ized, including PsycINFO, LexisNexis, and Hoovers. Freshmen only mentioned searching Google/Google Scholar, JSTOR, or "online." 52 In further comparison, freshmen did not seem to be aware that searching required multiple steps such as selecting search terms, trying different search terms and generally learning to use the databases and catalog. Nor did they appear aware that there were different databases from which to choose and that these databases might cover different subjects. Furthermore, as indicated by the obstacles freshmen encountered and where they turned for help, freshmen were definitely not aware that librarians are experts at these steps and at using these resources. This change in the type of help seniors sought from librarians and other experts reflects what seems to be an overall change in seniors' collective research process and understanding of it.

Seniors and freshmen also differed in their perceptions of who embodies authoritative knowledge. Seniors, unlike freshmen, sought help from people whom they considered experts at different aspects of the research process. In other words, seniors knew enough about the process to see the need for experts and saw librarians as experts of one thing and instructors of something else and turned to each, accordingly. As indicated in table 1, seniors sought help with the assignment parameters and content from their instructors. Seniors did not turn to instructors for help performing searches. They sought help performing searches from librarians first and foremost and sometimes from their peers. Seniors turned to their peers primarily for help proofreading. None of the seniors turned to their parents for help, and, in response to being asked whom they asked for help, two specified why with similar responses stating, "As far as family members-not really-because I'm the first to go to college, but they're not." This is a stark contrast to characteristic freshmen statements such as "my family is really smart so I asked them." Seniors seemed to recognize the need for expertise and that there were experts available to them. Only one senior turned to a family member for help, and this student did not turn to her parents but to her husband and only for help with proofreading. These findings both parallel those of Head and Eisenberg who interviewed sophomores, juniors, and seniors and found that this group of students discerned between experts as well in that they turned to family and 
friends for help evaluating information for personal projects, but turned to their instructors for help evaluating information for use in their courses..$^{53}$ Head and Eisenberg found that students turned to instructors more than librarians for help, ${ }^{54}$ but this difference in findings might stem from their inclusion of lowerclassmen among their interviewees and/or their more specific focus on whom students asked for help with evaluation. This study at UIC asked more generally about whom students asked for help and that clearly elicited answers that included searching as well as evaluating information.

As shown in table 1, freshmen behaved differently in other ways as well. Freshmen turned to their instructors for nearly every aspect of the research process and turned to librarians, primarily, for finding books. Likewise, freshmen turned to their peers for help searching and learning to search, whereas seniors looked to peers primarily for proofreading help. This change inherently suggests two things: seniors have come to realize, first of all, that research involves several different steps, and, second, that expertise on each of these steps exists for them to seek out. Moreover, they better know where to seek such expertise.

Finally, while freshmen asked for help with almost every aspect of the research process, seniors asked for help with significantly fewer things. This shortened list parallels their perceived sense of self-sufficiency. As described in the Searching and Source Selection sections, their collective sense of self-sufficiency seems warranted. They appear to have

\begin{tabular}{|c|c|c|}
\hline \multicolumn{3}{|c|}{$\begin{array}{c}\text { TABLE } 1 \\
\text { Types of Help Sought }\end{array}$} \\
\hline & Seniors & Freshmen $^{55}$ \\
\hline Librarian & $\begin{array}{l}\text { - using databases/catalog } \\
\text { - } \text { selecting search terms } \\
\text { - } \text { physically getting to sources }\end{array}$ & $\begin{array}{l}\text { - } \text { physically getting to sources } \\
\text { - } \text { selecting search terms } \\
\text { - using databases/catalog }\end{array}$ \\
\hline Instructor/TA & $\begin{array}{l}\text { - } \text { selecting content } \\
\text { - } \text { selecting topic } \\
\text { - } \text { proofreading } \\
\text { - } \text { selecting sources }\end{array}$ & $\begin{array}{l}\text { - } \text { progress check } \\
\text { - } \text { proofreading } \\
\text { - } \text { selecting topic } \\
\text { - } \text { honing topic } \\
\text { - identifying where to search for } \\
\text { sources } \\
\text { - getting approval of sources } \\
\text { - } \text { selecting content } \\
\text { organizing project }\end{array}$ \\
\hline Friend/Classmate & $\begin{array}{ll}\text { - } & \text { proofreading } \\
\text { - } & \text { selecting content } \\
\text { - } & \text { organizing project }\end{array}$ & $\begin{array}{l}\text { - } \text { proofreading } \\
\text { - } \text { selecting search terms } \\
\text { - } \text { how to use databases/catalog } \\
\text { - } \text { where to search for sources } \\
\text { - } \text { selecting content } \\
\text { - } \text { organizing project }\end{array}$ \\
\hline Writing Center & - proofreading & $\begin{array}{ll}\text { - } & \text { selecting content } \\
\text { - } & \text { organizing project }\end{array}$ \\
\hline Family Member & - proofreading & $\begin{array}{l}\text { - } \text { identifying where to search for } \\
\text { sources } \\
\text { - } \\
\text { - } \text { selecting content } \\
\text { organizing project }\end{array}$ \\
\hline
\end{tabular}


learned quite a bit more about the research process than freshmen knew and are probably better able to, as one senior put it, "hack it on my own." Seniors' not asking for help seems to be the result of their having received past help, which led to their self-sufficiency.

As with Yee and Padilla, researchers at UIC found that first-generation college students initially need help with the institutional heuristics involved in higher education, such as how to make use of the library, from whom to seek help, and setting accurate expectations of what college work requires. ${ }^{56}$ This study at UIC reflected Padilla's findings ${ }^{57}$ that students who have not learned these practicalities from their parents are still able to acquire them during their time at college and to succeed as students.

\section{The Library in Retrospect}

When asked what the library could have done differently to help them, seniors expressed themselves in more specific terms that indicated a familiarity and comfort level vis a vis the library. The freshmen spoke generically about not knowing the librarians, saying it would be most helpful if librarians were nice, friendly, and nonjudgmental. ${ }^{58}$ Ten percent of students wanted more and better computers including touchscreen computers. Technology was clearly an important component of the library to them. A couple of students wished the space were more modern and colorful with interesting art on the walls. Some mentioned noise as a problem; others wanted all their required texts to be in the library and for everything to be available in full-text form online. Of the seniors, 15 percent mentioned that the librarians could have helped them search their topics better with better keywords. (While this finding indicates some dissatisfaction with librarians, it reflects the findings in the Help section in that seniors, unlike freshmen, turned to librarians for helpspecifically, help beyond finding a book on the shelf.) Again, 10 percent of seniors mentioned that a more user-friendly website would be helpful. Others were ultraspecific about problems such as the printers always getting stuck (printers are not handled by the library at UIC), that an English writing tutor or an ESL person in the library would be helpful, that the catalog should include a picture of the book and that ILL was too slow. Finally, 15 percent of seniors felt the library had done everything it could to help them succeed. One stated, "I found what I needed after asking help, I don't know what else they could have done more." Another described a situation in which the librarian turned a negative into a positive by showing the frustrated student how to find books on the shelf, after which the student came away with three or four books and not just one.

Of the seniors, approximately 28 percent turned out to be transfer students, a statistic that closely mirrors the approximately 29 percent of transfer students among the campus population at large..$^{59}$ From this group, some unexpected information emerged. Much like the freshmen in the ERIAL project, these transfer students experienced anxiety about the overwhelming size of a research library compared to their "home" libraries and were also reluctant to ask librarians for assistance. It became apparent that entering a new research university environment was not an easy transition for them. It took time for them to understand the community's expectations of them and how they were to fulfill those expectations. The transfer students described struggling with complex assignments, but they also confessed to not using the library. Upon reflection, each one said that they wished they had known about the library's resources. Because the UIC Library does not offer library instruction sessions specifically for transfer students, the transfer student interviewees had not had a UIC Library instruction session, unlike most of the other senior interviewees. Possibly as a result, the transfer students did not figure things out until much later, 
if then. The transfer students also expressed regret at not having had a library session like the ones they had had at their former schools. This finding supports the conclusions of Jacobson and Mark who looked at First Year Experiences at the University of Albany and Messiah College. Their study asserts that beginning information literacy instruction in the students' first year is optimal. ${ }^{60}$ Likewise, Tyckson finds that library instruction has a profound effect on the information literacy, in particular, of first-generation students. ${ }^{61}$

\section{Where Research Takes Place}

In the ERIAL study, one very interesting fact that emerged was that many freshmen discussed returning to their high school libraries to do their college research. ${ }^{62}$ As this surprised the investigators, they added a question for the seniors about where they study. Researchers asked seniors, "Where do you do your research?" They found that a significant change had occurred with seniors' use of libraries. Unlike the freshmen, no seniors mentioned going back to their old high school or public library. Freshman explained that they returned to those institutions because they were familiar to them and the university library seemed overwhelming. ${ }^{63}$ Seniors appear to have become familiar enough with the university library to both see it as convenient and useful. The freshmen spoke of the UIC Library as being big and difficult to navigate. ${ }^{64}$ For seniors, the UIC library appeared to be the more familiar library. This idea is supported by the fact that seniors described the library in much more specific language. They had developed favorite study locations, such as "behind the reserve desk," "on the second floor in the corner...," and on the "4th floor with all the study groups." As indicated by these comments, at some point the university library became comfortable for them, and they got over being overwhelmed. Of the seniors, 70 percent specifically mentioned studying at the library, while 65 percent also studied at home. They said that, because of their other responsibilities, most have to work at home, and they come to the library a lot in between classes. A couple of students said they did their work wherever they found a computer; one student even used her phone on the way home.

\section{Conclusions}

This study found that many seniors have developed additional, necessary research skills and a much more complex understanding of research as a process. In addition, the researchers discovered some of the details that constitute this change as well as some unexpected results.

In terms of searching, seniors had parsed the concept of "online" and spoke fluently of the particulars of library locations, resources, and services. Most important, they spoke of research as an iterative process. Seniors, like freshmen, selected the number and types of sources according to the project parameters set by their instructors. However, seniors approached these tasks more rigorously and with greater understanding of their options, seemingly with a set of standards of their own that went beyond the instructors' requirements. Seniors generally displayed additional skill at finding and evaluating sources.

Seniors, like freshmen, still struggled with time management, topic selection, an unawareness of the library's available services and resources, as well as searching for and getting their hands on sources. However, seniors spoke much more specifically about the searching process and the resources, indicating an increasing familiarity and comfort with both performing research and using the library.

In facing these obstacles, seniors worked much more independently and adeptly than freshmen. Unlike freshmen, seniors looked to librarians more frequently for assistance and did so with a clearer awareness and understanding of librarians' expertise. 
With respect to what the library could have done differently, most students either concurred that the library had done all it could or expected better help from librarians in terms of search terms. Both perspectives represent a change from the expectations of freshmen.

Among seniors at UIC, the sense of familiarity had shifted from the library they used in high school to the university library. It became clear that seniors had come to understand the difference between their high school, community college, or public library and a research library.

The fact that some of the seniors were transfer students unexpectedly emerged from the interviews. The transfer students proved quite unfamiliar with the library as the result of circumstances that strongly suggest that library instruction can make a significant difference in students' research processes. Interviews with these transfer students yielded new information about what the library could do to help them be successful.

In general, the comparison of firstgeneration college seniors to freshmen brought forth both predicted and unexpected information. Unlike most prior studies, the separate analysis of freshmen and seniors allowed for the data to reflect changes as a result of increased college experience. Seniors appear to have acquired more advanced information literacy skills; and, similar to the findings of Padilla, ${ }^{65}$ this finding shows that students who may arrive with less heuristic knowledge about campus life can successfully acquire it. The study also identified some gaps in the services the library might provide. Overall, the information from the ERIAL Project and this related comparison will allow the UIC Library to hone services and evaluate materials to benefit its users. This study employed a student emic perspective, which Padilla states "may open new ways of understanding student retention and possible strategies for increasing graduation rates." 66 Thus, this study may also serve as an example to other institutions of the value of qualitative evaluation. Such approaches can uncover information relevant to academic missions of the library and university as a whole.

\section{Impact on Strategic Goals}

As a result of these studies, the UIC Library has undertaken several new initiatives and has put together a service priority list that will be part of the nearterm reference department strategic goals. First, understanding that students have a variety of responsibilities at school and at home, the department is designing guides to meet their needs. The researchers contacted the university department responsible for orientation, and it agreed to schedule library sessions specifically designed for transfer students during their orientation sessions. The library will also offer two sessions each semester for transfer students.

Also, the library is going to revive its involvement in orientation sessions for incoming freshmen as well as new faculty, commuter students, international students, and graduate students. The library will now introduce its resources and services to these people in a more basic and systematic way, with tours and general orientation programs as well as targeted instruction and consultation. In this study, the students have shown that the library can make a difference by helping students attain the expertise, ability, and skill to search for, locate, and evaluate information necessary for academic success.

Furthermore, the study showed that, regardless of the disadvantages with which students arrive at college, at some point before they graduate, college appears to provide them with the tools they need to compete with their peers. In particular, the library has a role to play in this process. Thus, these findings have implications for higher education beyond the role of the library. 


\section{Future Research}

It would be informative to determine at which point the above changes in students' research processes occur (whether sophomore year, junior year, or some other juncture). Furthermore, as UIC students have graduated from a wide range of high schools, ${ }^{67}$ many of which are highly ranked on a national scale ${ }^{68}$ the researchers, like those at $\mathrm{UAL}$, consider it possible that other groups in addition to first-generation college students may have encountered similar obstacles during the research process. ${ }^{69}$ It is possible that high school experience and other parameters that did not surface in the two studies at UIC might be predictors of academic success as much as parents' level of education. Thus, it would be useful to explore additional factors in predicting and determining academic success. Other factors to consider might include: language acquisition, willingness to ask for help, and high school ranking and curriculum. A similar, comparative study of non-first-generation college students might also help pinpoint more determinative variables.

\section{Appendix A \\ Student Interview Protocol}

\section{A. Past research projects}

[A.C1] Tell me about the last research paper or project you worked on.

[A.C2] What problems or obstacles did you encounter while working on this assignment? (Probe for specifics, e.g. finding good books and articles, time management issues, difficulty in judging appropriate source materials, etc.)

\section{B. Student research process}

[B.C1] Did you search online? Did you use print materials? How did you choose what you used?

[B.C2] How did you know when you had enough sources?

[B.C3] How did you know when you had the right kind of sources?

[B.C4] Were there any problems or obstacles that you encountered while working on the assignment?

[C.C3] Where do you do your research?

\section{Seeking help}

[C.C1] Did you ask anyone for help? Who did you ask and why?

[C.C2] What help do you think the library here could have offered you? [Probe: What other resources, or physical materials and technology, do you think the library could offer? What services, or help from staff, do you think the library could offer?] Could the library have done anything differently?

\section{Demographics:}

What language do you speak at home?

Where did you attend high school?

What is your major? 


\section{Notes}

1. UIC Office of Institutional Research, UIC Student Databook Fall 2011, Section B, 4, available online at www.oir.uic.edu/students/pdfs/sdb/SDBF10SectB.pdf [accessed 1 April 2012].

2. UIC Office of Institutional Research, UIC Student Databook Fall 2010, Section C, 4, available online at www.oir.uic.edu/students/pdfs/sdb/SDBF10SectC.pdf [accessed 1 November 2011].

3. UIC Office of the Vice Chancellor for Student Affairs, Who Are the First Generation Students at UIC? An Examination of the Fall 2002 Beginning Freshman Class, available online at http://tigger. uic.edu/ ardinger/assessment/parent-ed.html [accessed 1 November 2011].

4. Matthew P. Long and Roger C. Schonfeld, 2010. Ithaka S+R library survey 2010: Insights from the U.S. academic library directors. http://www.sr.ithaka.org/research-publications/uslibrary-survey-2010 [accessed 16 May 2013].

5. Derek Rodriguez, " Understanding Library Impacts on Student Learning," in In the Library with the Lead Pipe (2011), available online at www.inthelibrarywiththeleadpipe.org/2011/ understanding-library-impacts-on-student-learning/ [accessed 1 November 2011].

6. Gina Hunter and Dane Ward, "Students Research the Library: Using Student-Led Ethnographic Research to Examine the Changing Role of Campus Libraries," College E Research Libraries News 72, no. 5 (May 2011): 265.

7. Susann deVries, Robert Kelly, and Paula M. Storm, “ Moving beyond Citation Analysis: How Surveys and Interviews Enhance, Enrich, and Expand Your Research Findings," College $\mathcal{E}$ Research Libraries 71, no. 5 (Sept. 2010): 464.

8. Michelynn McKnight, "Beyond Surveys: Methods for Finding Out 'Why?'” Journal of Hospital Librarianship 1, no. 2 (2001): 31-39.

9. Clifford Geertz, Works and Lives: The Anthropologist as Author (Stanford, Calif: Stanford University Press, 1988).

10. Ibid., 16.

11. Jordan G. Yee, "Librarians as Matchmakers: Connecting Seniors in Their Capstone Semester," Reference Services Review 35, no. 2 (2007): 257-64.

12. Raymond V. Padilla et al., "Developing Local Models of Minority Student Success in College," Journal of College Student Development 382, no. 2 (1997): 125-35.

13. Catherine Haras, Edward M. Lopez, and Kristine Ferry, "(Generation 1.5) Latino Students and the Library: A Case Study," Journal of Academic Librarianship 34, no. 5 (2008): 425-33.

14. David A. Tyckoson, "Library Service for the First-Generation College Student," in Teaching the New Library to Today's Users (Chicago: Neal-Schuman, 2000), 89-105.

15. Jan Conway, Tania Olsson, and Nick Veale, "Make the Numbers Count: Improving," SCONUL Focus 45 (2009): 90-93.

16. Firouzeh Logan and Elizabeth Pickard, "First-Generation College Students: Their Research Process," in College Libraries and Student Culture: What We Now Know, 1st ed., eds. Andrew Asher and Lynda Duke (Chicago: American Library Association, 2011).

17. Melissa Gross and Don Latham, "Undergraduate Perceptions of Information Literacy: Defining, Attaining, and Self-assessing Skills," College E Research Libraries 70, no. 4 (July 2009): 336-50.

18. Alison J. Head and Michael B. Eisenberg, Truth Be Told: How College Students Evaluate and Use Information in the Digital Age (Seattle: The Information School, University of Washington, 2010).

19. Arlene Greer, Lee Weston, and Mary L. Alm, "Assessment of Learning Outcomes: A Measure of Progress in Library Literacy," College E Research Libraries 52 (Nov. 1991): 549-57.

20. Jill Coupe, "Undergraduate Library Skills: Two Surveys at Johns Hopkins University," Research Strategies 11 (Fall 1993): 188-201.

21. Logan and Pickard, "First-Generation College Students."

22. Ibid., 114-23.

23. Andrew D. Asher, Susan Miller, and David Green, "Ethnographic Research in Illinois Academic Libraries: The ERIAL Project," in College Libraries and Student Culture: What We Now Know, 1st ed., eds. Andrew Asher and Lynda Duke (Chicago: American Library Association, 2011), 12-13; Barney Glaser and Anslem Strauss, The Discovery of Grounded Theory: Strategies for Qualitative Research (Chicago: Aldine, 1967); The SAGE Handbook of Grounded Theory, eds. Antony Bryant and Kathy Charmaz (Los Angeles: Sage, 2010).

24. The SAGE Handbook of Grounded Theory, 114-16.

25. Ibid., 115.

26. Gross and Latham, "Undergraduate Perceptions of Information Literacy," 341.

27. Logan and Pickard, "First-Generation College Students," 115-16. 
28. Ibid., 122.

29. Ibid., 116-18.

30. Ibid.

31. Ibid.

32. Ibid.

33. Ibid., 117.

34. Ibid., 118.

35. Ibid.

36. Ibid.

37. Ibid.

38. Ibid.,116-18.

39. Ibid., 118-19.

40. Ibid., 116-20.

41. Ibid., 119.

42. Ibid.

43. Ibid.

44. Ibid.

45. Ibid., 119-20.

46. Head and Eisenberg, "Truth Be Told," 1.

47. Gross and Latham, "Undergraduate Perceptions of Information Literacy," 345-46.

48. Hunter and Ward, "Students Research the Library," 266.

49. Logan and Pickard, "First-Generation College Students," 121.

50. Ibid., 121-23.

51. Ibid., 121.

52. Ibid., 114-120.

53. Head and Eisenberg, "Truth Be Told," 1.

54. Ibid., 53.

55. Logan and Pickard, "First-Generation College Students," 121.

56. Yee, "Librarians as Matchmakers," 263; Padilla et al., "Developing Local Models," 126-27.

57. Padilla et al., "Developing Local Models," 129-35.

58. Logan and Pickard, "First-Generation College Students," 123.

59. UIC Office of Institutional Research, UIC Student Databook Fall 2010.

60. Trudi Jacobson and Beth L. Mark, "Separating Wheat from Chaff: Helping First-Year Students Become Information Savvy," Journal of General Education 49 (2000): 277.

61. Tyckoson, "Library Service for the First-Generation College Student," 104.

62. Logan and Pickard, "First-Generation College Students," 120.

63. Ibid.

64. Ibid.

65. Padilla et al., "Developing Local Models," 126-27.

66. Ibid., 134.

67. UIC Office of Institutional Research, UIC Student Databook, 2012, Section D, 6-7, available at http://www.oir.uic.edu/students/pdfs/sdb/SDBF12SectD.pdf [accessed 16 May 2013]

68. Gamerman, Ellen, Chun, Juliet, Park, SungHa and Jackson, Candace. "High schools: How the schools stack up." The Wall Street Journal Online (12/28/2007). http://online.wsj.com/public/ resources/documents/info-COLLEGE0711-sort.html [accessed 10 October 2010].

69. Conway, Olsson, and Veale, "Make the Numbers Count," 93. 